\title{
A Cd-, Cr-, Ni-, Pb- és Zn-koncentráció változása a talajoldatban szennyezés és savterhelés hatására, laboratóriumi kísérletben
}

\author{
CSILLAG JULIANNA, LUKÁCS ANDRÁS, BUJTÁS KLÁRA és \\ PÁRTAY GÉZA
}

MTA Talajtani és Agrokémiai Kutatóintézet, Budapest

A napjainkban tapasztalható, egyre növekvő mértékű környezetszennyezés következtében mind nagyobb mennyiségü nehézfémvegyület kerül a talajba. Ott hosszú időn keresztül megőrizhetik potenciális mérgező hatásukat, a környezeti feltételek változása (a talaj fokozódó savasodása, a talaj száradás-nedvesedés ciklusai, a redox-viszonyok megváltozása stb.) következtében mobilizálódhatnak; a talajoldatba került nehézfémek a szelvényben lemosódhatnak, az ivóvízkészletbe kerülhetnek, illetve a növény számára felvehetővé válhatnak, a táplálkozási láncba juthatnak („kémiai időzített bomba”) (STIGLIANI et al., 1991; GYÖRI et al., 1996; ALLOWAY, 1997; GOULDING \& BLAKE, 1998).

A nehézfémek mobilizálódásának egyik fő oka az, hogy a talajt érő savterhelés következtében, a pH csökkenésével a talajásványokon, humuszanyagokon való kötődésük megváltozhat, vegyületeik oldhatósága többnyire nő. Számos irodalmi adat található arra vonatkozóan, hogy a $\mathrm{pH}$ változása különbözőképpen befolyásolja az egyes fémek mobilitását, illetve megkötődését a talajban (FÖRSTNER, 1988; KABATA-PENDIAS \& PENDIAS, 1992; YoNG et al., 1992; KARUCZKA \& BlASKÓ, 1993; SCHUlTe, 1994; EVANS et al., 1995; REDDY et al., 1995; FILEP, 1998; WELP \& BRÜMMER, 1999). A savanyodásra legérzékenyebbek a kis pufferkapacitású: nem karbonátos, kis kicserélődési kapacitású és bázistelítettségü, humuszban szegény, duzzadó agyagásványokat kis mennyiségben tartalmazó homoktalajok (STEFANOVITS, 1989; VÁRALLYAY et al., 1989; FILEP, 1999).

A nehézfémek által okozott környezeti kockázat becslése céljából fontos annak ismerete, hogy azok mekkora hányada kötődik meg a talajban - az adott $\mathrm{pH}$ és nedvességviszonyok esetén - és mennyi kerül át a talaj folyadékfázisába. A nehézfémek megjelenése a talajoldatban az egyik fontos környezet-szennyezettségi indikátor (KABATA-PENDIAS, 1995). 
A talajoldat bolygatatlan és bolygatott szerkezetü, megszárított és adott nedvességtartalomra visszanedvesített talajból történő kinyerésére számos helyszíni (in situ) és laboratóriumi eljárás ismert a szakirodalomból. A legfontosabb talajoldat nyerési módszerek előnyeit és hátrányait az 1. táblázatban foglaltuk össze. Minthogy a folyadékfázis összetételét az elválasztási módszer nagymértékben befolyásolja, az adatok interpretálásához a közleményekben azt minden esetben részletesen közlik. A különbözö talajoldat kinyerési technikákról összehasonlító vizsgálatok (ZABOWSKI \& UGOLINI, 1990; BUFFLAP \& ALLEN, 1995; KELLER, 1995; GIESLER et al., 1996) és összefoglaló értékelő munkák (SOON \& WARREN, 1993; DEL CASTILHO, 1994; WOLT, 1994) is rendelkezésre állnak.

Bár a szakirodalomban számos cikk közöl adatokat a talaj folyadékfázisának nehézfém-koncentrációiról (ALlOWAY \& MORGAN, 1986; CAMPBELL \& BeCKetT, 1988; KABATA-PENDIAS \& PENDIAS, 1992; LORENZ et al., 1994; GOODDY et al., 1995; KABATA-PENDIAS, 1995), kevés esetben jellemzik a leválasztásra kerülő oldat energiaállapotát (KELLER, 1995; SMAL et al., 2000). Az MTA Talajtani és Agrokémiai Kutatóintézetben korábban szikes talajok vizsgálatára kifejlesztett, nyomásmembrános készülékkel (VÁRALLYAY \& RÉDLYNÉ, 1977; CSILLAG \& RÉDLY, 1989), majd centrifugálással végzett oldat elválasztási módszer (CSILLAG et al., 1995) a hervadáspontnak ( $\mathrm{pF} 4,2=-1500 \mathrm{kPa}$ (= -15 bar)) megfelelőnél kisebb erőkkel kötött, a növény számára talajfizikai szempontból felvehető talajoldat kinyerését teszi lehetővé. Ez továbbfejlesztve, alkalmassá vált környezetkémiai vizsgálatokra is, többek között a talajoldatba kerülő nehézfémek koncentrációjának meghatározására (CSILLAG et al., 1998, 1999). A talajoldat kinyerésének ezen az elven alapuló centrifugálási módszerét még jelenleg is kevés helyen alkalmazzák (SUAREZ, 1999).

Laboratóriumi kísérleteink során azt kívántuk modellezni, hogy bolygatott szerkezetü talajminták különböző mértékü nehézfém- és savterhelése esetén, szennyvíziszap jelenlétében, illetve anélkül, mekkora a nehézfémek talajoldatba jutó mennyisége. A nehézfémek közül a kadmiumot, krómot, nikkelt, ólmot és cinket vizsgáltuk; ezek az elemek jelentősebb mennyiségben fordulhatnak elö a különböző szennyvizekben és szennyvíziszapokban, különböző mértékben fitotoxikusak és a táplálékláncba jutva az emberre is veszélyesek lehetnek.

\section{Anyag és módszer}

\section{Nehézfémterhelés hatása}

Különböző hazai talajok (2. táblázat) felszíni rétegének szokásos módon elökészített légszáraz mintáit nehézfémsó- (nitrát-) tartalmú többkomponensü oldatokkal, illetve a fémsókkal dúsított kommunális szennyvíziszappal kezeltük. A koncentrációkat a mezőgazdaságban felhasználható szennyvíziszapok megenge- 


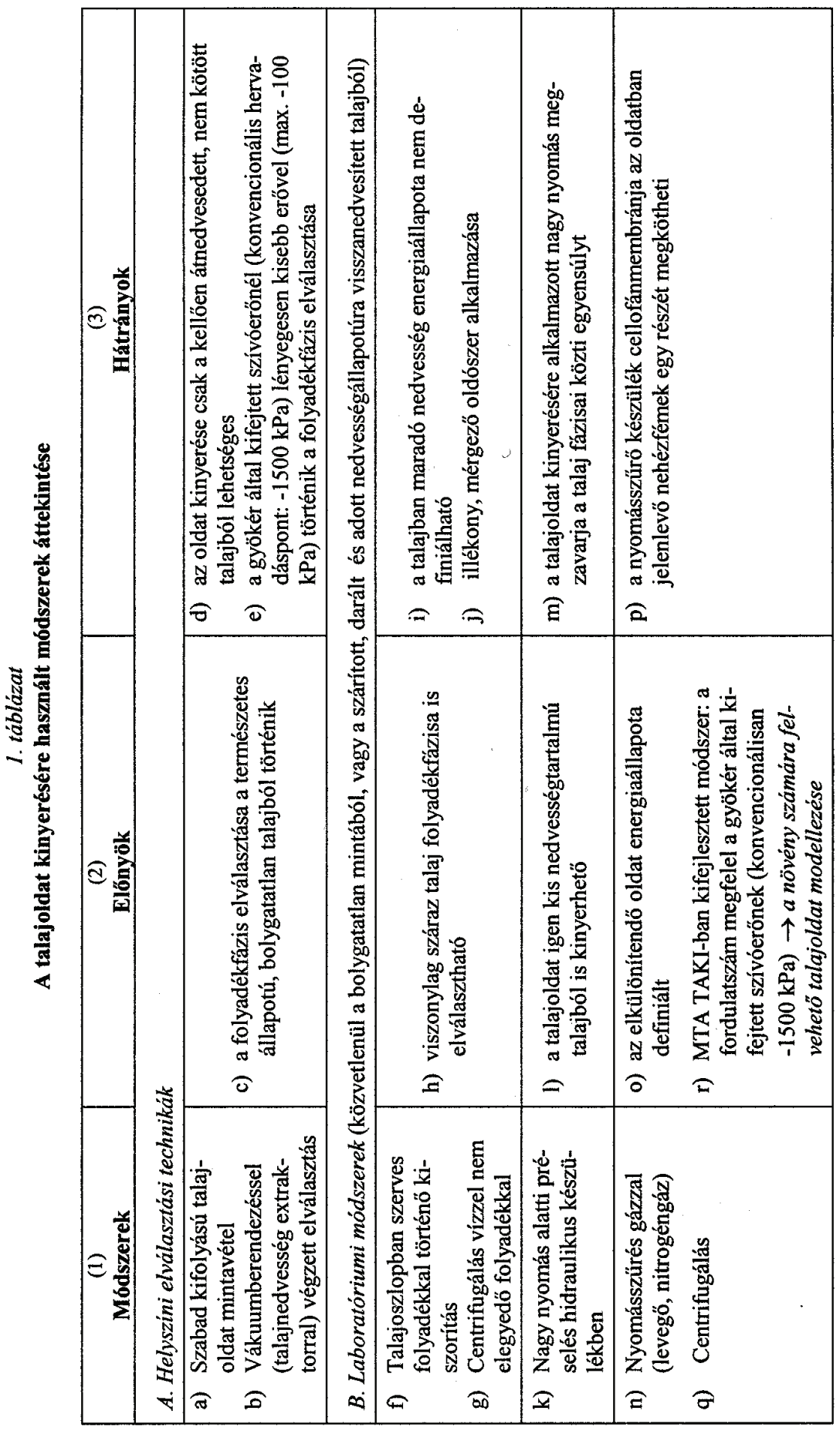




\section{2. táblázat}

A talajok főbb fizikai és kémiai tulajdonságai

\begin{tabular}{|c|c|c|c|c|c|c|c|c|}
\hline \multirow[t]{2}{*}{$\begin{array}{c}\text { (1) } \\
\text { Talaj }\end{array}$} & \multirow{2}{*}{$\begin{array}{c}(2) \\
\text { Mélység } \\
\text { cm }\end{array}$} & \multicolumn{2}{|c|}{ pH } & $\mathrm{CaCO}_{3}$ & $\begin{array}{c}\text { (3) } \\
\text { Humusz }\end{array}$ & \multirow{2}{*}{$\begin{array}{c}\text { (4) } \\
\text { T érték } \\
\text { me/100g }\end{array}$} & $<\mathbf{0 , 0 2}$ & $<0,002$ \\
\hline & & $\mathrm{H}_{2} \mathrm{O}$ & $\mathrm{KCl}$ & \multicolumn{2}{|c|}{$\%$} & & \multicolumn{2}{|c|}{$\mathrm{mm}(\%)$} \\
\hline 1. & $5-15$ & 4,3 & 3,2 & 0 & 1,6 & 20,7 & 40,8 & 27,8 \\
\hline 2. & $5-15$ & 5,6 & 4,5 & 0 & 1,3 & 6,7 & 20,4 & 12,7 \\
\hline 3. & $0-20$ & 7,7 & 7,0 & 6,6 & 2,8 & 28,3 & 35,8 & 22,1 \\
\hline
\end{tabular}

Talajok: 1. Savanyú kémhatású agyagbemosódásos barna erdőtalaj (Ragály); 2. Gyengén savanyú humuszos homoktalaj (Somogysárd); 3. Csernozjom talaj (Pusztaszabolcs). T érték $=$ kationcsere kapacitás; $<0,02 \mathrm{~mm}=$ leiszapolható rész (iszap + agyag); $<0,002 \mathrm{~mm}=$ agyagfrakció

dett fémtartalmának felső határát figyelembe véve állítottuk be (MI-08-17351990; 3. táblázat). A megengedett (1-szeres, 1 Me $(\approx$ Metal)) terhelésen kívül provokatív, 10-szeres és 100 -szoros túlterhelést is alkalmaztunk $(10 \mathrm{Me}$ és $100 \mathrm{Me})$, a nagymértékü helyi, pontszerü felhalmozódások hatásának modellezésére.

A talajmintákat a fémsóoldatokkal a szabadföldi vízkapacitásnak ( $\mathrm{pF}$ 2,3 = $-20 \mathrm{kPa}$ vízpotenciál értéknek) megfelelően nedvesítettük be. Egy heti állás és közben háromszori átkeverés után centrifugálással választottuk el a talajban a pF 4,2 és 2,3 (-1500 és -20 kPa) közötti erővel kötött folyadékfázist. Ily módon a holtvíznél gyengébben kötött, a növény számára felvehetö talajoldatot modelleztük (jelen kísérletben, szabadföldi vízkapacitásnál: hasznosítható, v. diszponibilis víz), és a szennyezett talaj nehézfémtartalmának legmobilisabb részét tudtuk becsülni.

\section{3. táblázat}

A megengedhető fémtartalom felső határa a mezőgazdaságban felhasználható szennyvíziszapokban (MI-08-1735-1990 MÉM Ágazati Múszaki Irányelv alapján), valamint a talajban*

\begin{tabular}{|c|c|c|}
\hline Elem & $\begin{array}{c}(2) \\
\text { Iszapban } \\
\text { mg/kg szárazanyag }\end{array}$ & $\begin{array}{c}(3) \\
\text { Eredő talajterhelés (1Me) } \\
\text { mg/kg talaj* }\end{array}$ \\
\hline $\mathrm{Cd}$ & 15 & 0,125 \\
$\mathrm{Cr}$ & 1000 & 8,33 \\
$\mathrm{Ni}$ & 200 & 1,67 \\
$\mathrm{~Pb}$ & 1000 & 8,33 \\
$\mathrm{Zn}$ & 3000 & 25,0 \\
\hline
\end{tabular}

* 500t, $5 \%$ szárazanyag-tartalmú szennyvíziszap/ha dózis, a szántott rétegbe $20 \mathrm{~cm}$ mélységig bedolgozva (számított érték) 
A természetes nedvességtartalmú mintákból rendszerint csak kis térfogatú talajoldat nyerhető ki; a koncentrációkat ezért az elemek egyidejü mérését lehetővé tevő, polikromátorral ellátott JARREL ASH készülékkel határoztuk meg, ICP spektrometriás módszerrel.

\section{4. táblázat}

A talajoldat kinyerés módszerének hibája: a folyadékfázis elemkoncentrációi (mg/L) szabadföldi és maximális vízkapacitásnak megfelelő talajnedvességtartalomnál (savanyú kémhatású agyagbemosódásos barna erdőtalaj: Ragály, 100Me)

\begin{tabular}{|l|c|c|c|c|c|}
\hline \multirow{2}{*}{ Statisztikai mutató } & \multicolumn{5}{|c|}{ (2) Elemek } \\
\cline { 2 - 6 } & $\mathbf{C d}$ & $\mathbf{C r}$ & $\mathbf{N i}$ & $\mathbf{P b}$ & $\mathbf{Z n}$ \\
\hline Szabadföldi vízkapacitás & \multicolumn{5}{|c|}{} \\
$\mathrm{x}$ & 35,5 & 244 & 491 & 352 & 7660 \\
$\mathrm{~s}$ & 1,2 & 9 & 11 & 14 & 160 \\
$\mathrm{CV}(\%)$ & 3,3 & 3,6 & 2,2 & 4,0 & 2,1 \\
$\mathrm{~h}( \pm)$ & 1,1 & 9 & 11 & 14 & 155 \\
Maximális vízkapacitás & \multicolumn{5}{|}{} \\
$\mathrm{x}$ & 26,4 & 189 & 359 & 259 & 5570 \\
$\mathrm{~S}$ & 1,1 & 7 & 5 & 9 & 50 \\
$\mathrm{CV}(\%)$ & 4,3 & 3,5 & 1,3 & 3,5 & 1,0 \\
$\mathrm{~h}( \pm)$ & 1,1 & 6 & 4 & 9 & 50 \\
\hline
\end{tabular}

Megjegyzés: $\mathrm{n}$ (az ismétlések száma) $=5 ; \mathrm{x}=$ átlagérték; $\mathrm{s}=$ szórás; $\mathrm{CV}=$ variációs koefficiens $(\%) ; \mathrm{h}=$ konfidencia határok $\mathrm{t}_{5 \%}$ szignifikancia szinten

Nehézfémmel terhelt talaj esetén, a talajoldat kinyerés módszerének reprodukálhatóságát a savanyú kémhatású agyagbemosódásos barna erdőtalaj nagymértékben (a megengedett terhelést 100-szorosan meghaladóan) szennyezett mintáján határoztuk meg. A minta-előkészítés, a folyadékfázis elválasztás és a kémiai elemzés együttes hibáját kifejező variációs koefficiens $(\mathrm{CV})$ értéke a vizsgált elemek esetén az $5 \%$-ot nem haladta meg (4. táblázat). A Somogysárdról származó homoktalaj esetén, a mért adatok reprodukálhatóságának ellenőrzésére minden kezelést (a fémsóoldatokkal, illetve a fémsókkal dúsított iszappal való terhelést, valamint a salétromsav oldatokkal történő kezelést) két ismétlésben végeztünk. A párhuzamos minták mérési adatai jól egyeztek; a számításokhoz, illetve a táblázatok és ábrák készitéséhez a két párhuzamos mérés átlagolt értékeit használtuk. 
Szennyvíziszap jelenlétének hatása

A szennyvíziszaphoz, melynek eredeti fémtartalma kisebb volt, vagy közel megegyezett a megengedett fémtartalommal, $100 \mathrm{Me}$ talajterhelésnek megfelelően adtuk a fémek nitrátsóit, és így kevertük a Somogysárdról származó homoktalaj légszáraz mintájához. Az iszap nedvességtartalma a talaj szabadföldi vízkapacitásának megfelelő nedvességtartalmat biztosította. A szennyvíziszap fontosabb jellemzői: szárazanyag-tartalom: 20,6 \%; izzítási maradék: 48,2 \%; pH: 7,8; Cd: 12,3; Cr: 217; Ni: 109; Pb: 210; Zn: 3030 mg/kg szárazanyag. Az iszap, és az iszappal kezelt talaj folyadékfázisát is centrifugálással választottuk el, majd az alkalmazott fémsómennyiség ismeretében kiszámítottuk, hogy az elemek mekkora hányada kötődött meg.

\section{Savterhelés hatása}

A megengedetthez képest 10- és 100-szoros mértékben nehézfémmel szenynyezett és megszárított talajmintákat (Ragály, Somogysárd) különböző adagú savterheléseknek vetettük alá. A talajokat $0 ; 0,001 ; 0,1$ és $1,5 \mathrm{~mol} / \mathrm{L}$ koncentrációjú $\mathrm{HNO}_{3}$ oldatokkal a szabadföldi vízkapacitásnak megfelelő nedvességtartalomra újranedvesítettük, majd egy heti állás és közben háromszori átkeverés után centrifugálással elválasztottuk a folyadékfázist.

Az igen nagy savterheléseket az esetleg előforduló kiugró lokális savanyító

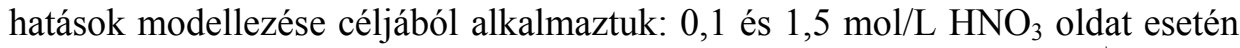
a ragályi talajnál 25 és 370 , a somogysárdi talajnál 16 és $235 \mathrm{mmol} \mathrm{H}^{+} / \mathrm{kg}$ talaj volt a savterhelés. Ez a savadag a somogysárdi talaj esetén például a ma-

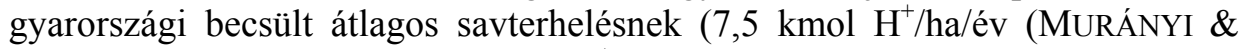

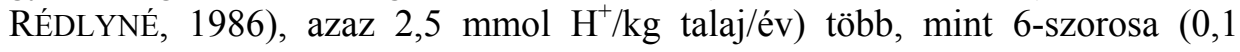
$\left.\mathrm{mol} / \mathrm{L} \mathrm{HNO}_{3}\right)$, illetve 94 -szerese $\left(1,5 \mathrm{~mol} / \mathrm{L} \mathrm{HNO}_{3}\right)$ volt.

\section{Kísérleti eredmények}

\section{Nehézfémterhelés hatása}

$\mathrm{Az}$ eredeti, terheletlen talajokban $(0 \mathrm{Me})$, és az iszapelhelyezési irányelvekben megengedett, azaz 1-szeres terhelésnek megfelelö kezeléskor is többnyire elhanyagolhatóan kicsi maradt a folyadékfázisban a nehézfémek koncentrációja (vagy a kimutatási határ alatt volt) mindhárom vizsgált talajnál (5. táblázat). Az 1-szeres terhelésnél a szennyező oldat nehézfémtartalmának közel $100 \%$-át megkötötték a talajok, még a kis pufferkapacitású homoktalaj is. A talajoldatban ekkor az elemkoncentrációk nagyságrendileg megegyeztek az ivóvízre, felszíni vizekre, a talajvízre vonatkozó határértékekkel (6. táblázat). 
A talajok folyadékfázisának elemkoncentrációi (mg/L) különböző Mértékü nehézfémterhelések esetén

\begin{tabular}{|c|c|c|c|c|c|}
\hline $\begin{array}{c}\text { (1) } \\
\text { Terhelés }\end{array}$ & Cd & $\mathbf{C r}$ & $\mathbf{N i}$ & $\mathbf{P b}$ & $\mathbf{Z n}$ \\
\hline \multicolumn{6}{|c|}{ A. Savanyú kémhatású agyagbemosódásos barna erdötalaj (Ragály) } \\
\hline $0 \mathrm{Me}$ & $<\mathrm{kh}$ & 0,01 & - & $<\mathrm{kh}$ & 0,7 \\
\hline $1 \mathrm{Me}$ & 0,01 & 0,04 & - & 0,1 & 1,3 \\
\hline $10 \mathrm{Me}$ & 0,7 & 1,4 & - & 0,8 & 190 \\
\hline $100 \mathrm{Me}$ & 39 & 340 & - & 410 & 7800 \\
\hline \multicolumn{6}{|c|}{ B. Gyengén savanyú humuszos homoktalaj (Somogysárd) } \\
\hline $0 \mathrm{Me}$ & $<\mathrm{kh}$ & 0,02 & 0,08 & 0,09 & 0,9 \\
\hline $1 \mathrm{Me}$ & 0,01 & $<\mathrm{kh}$ & 0,2 & $<\mathrm{kh}$ & 3,5 \\
\hline $10 \mathrm{Me}$ & 0,5 & 0,3 & 12 & 0,3 & 220 \\
\hline $100 \mathrm{Me}$ & 54 & 503 & 711 & 923 & 10660 \\
\hline \multicolumn{6}{|c|}{ C. Csernozjom talaj (Pusztaszabolcs) } \\
\hline $0 \mathrm{Me}$ & $<\mathrm{kh}$ & $<\mathrm{kh}$ & - & $<\mathrm{kh}$ & 0,3 \\
\hline $1 \mathrm{Me}$ & $<\mathrm{kh}$ & 0,1 & - & $<\mathrm{kh}$ & 0,4 \\
\hline $10 \mathrm{Me}$ & 0,01 & 0,4 & - & 0,2 & 0,9 \\
\hline $100 \mathrm{Me}$ & 0,2 & 0,07 & - & 0,2 & 17 \\
\hline
\end{tabular}

Megjegyzés: < kh: kimutatási határ alatt; -: nem mértük; 0Me: terheletlen talaj; $1 \mathrm{Me}$, $10 \mathrm{Me}$ és $100 \mathrm{Me}$ : a szennyvíziszapban megengedett max. nehézfémterhelés 1-, 10- és 100-szorosa; terhelés: többkomponensü nehézfém-nitrát oldattal; nedvességpotenciál: $-20 \mathrm{kPa}$

Nagyobb terheléseknél, a talajtulajdonságoktól függően, különböző mennyiségü nehézfém került a talajoldatba (5. táblázat). $\mathrm{A} \mathrm{CaCO}_{3}$-ot és a viszonylag több szerves anyagot tartalmazó csernozjom talaj folyadékfázisában a nehézfém-koncentrációk - a Zn kivételével - még 100-szoros túlterhelés esetén is elhanyagolhatóak voltak. Az erdő- és a homoktalajban 10-szeres terhelésnél a Niés Zn-koncentráció volt csak számottevő, de 100-szoros terhelésnél minden fém koncentrációja nagymértékben megnőtt a talajoldatban. A Cd-, Ni- és Zn-koncentrációjának aránya nagyjából megfelelt az eredeti terhelési arányoknak, míg a kevésbé mozgékony $\mathrm{Cr}$ és $\mathrm{Pb}$ terhelési arányukhoz képest jóval kisebb mennyiségben kerültek a folyadékfázisba.

A talajoldat koncentrációkat a hozzáadott mennyiség százalékában kifejezve (visszanyerési \%), a fémek sorrendje mobilitásukat (FöRSTNER, 1988; Kabata-Pendias \& Pendias, 1990, 1992; Evans et al., 1995) tükrözte (1. ábra). 


\section{6. táblázat}

Elemkoncentrációk határértékei vizekben $(\mathrm{mg} / \mathrm{L})$

\begin{tabular}{|c|c|c|c|c|c|}
\hline & $\mathbf{C d}$ & $\mathbf{C r}$ & $\mathbf{N i}$ & $\mathbf{P b}$ & $\mathbf{Z n}$ \\
\hline 1 & 0,005 & 0,05 & - & 0,05 & $0,2-1,0$ \\
2 & 0,005 & 0,05 & - & 0,05 & - \\
3 & 0,005 & 0,05 & 0,05 & 0,05 & $0,1-5,0$ \\
4 & 0,0055 & 0,033 & 0,020 & 0,057 & 0,33 \\
5 & 0,01 & 0,05 & - & 0,05 & 5,0 \\
6 & $0,0005-0,002$ & $0,01-0,05$ & $0,015-0,05$ & $0,005-0,05$ & $0,05-0,1$ \\
7 & 0,005 & 0,05 & - & 0,05 & 1,0 \\
8 & 0,006 & 0,03 & 0,075 & 0,075 & 0,8 \\
9 & 0,01 & 0,10 & 0,20 & 5,0 & 0,50 \\
\hline
\end{tabular}

1. ivóvíz (MSz-450/1-1989); 2. ivóvíz (WHO-Guidelines for drinking water quality; cit. in Fresenius et al., 1988, 726.); 3. ivóvíz (Directive of the Council of the European Communities on the quality of water for human consumption; maximum admissible concentration (MAC); cit. in FRESENIUS et al., 1988, 740-742.); 4. folyóviz (river water, Rhine, Germany; cit. in KABATAPendias \& PENDIAS, 1990); 5. felszini vizek (surface water quality criteria of US Dept. of Interior, Fed. Water Pollut. Control Admin; cit. in ADRIANO, 1986, 34.); 6. felszíni vizek (MSz 12749, 1993); 7. felszín alatti vizek (MI-10-433/3-84); 8. talajviz (provisional Dutch soil sanitation standards for groundwater (cit. in DEL CASTILHO et al., 1996); 9. öntözövíz (irrigation water; guidelines, cit. in TANJI, 1990, 232-234.)
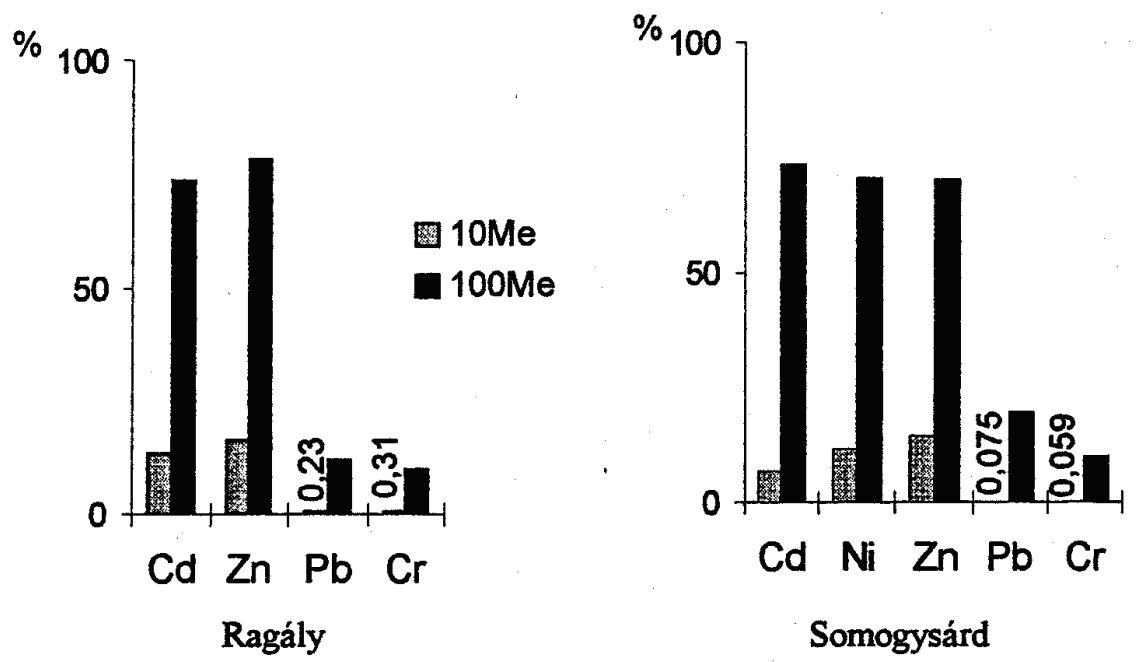

1. ábra

Nehézfém-koncentrációk a terhelés százalékában a talajok folyadékfázisában $\%=100 \cdot \mathrm{c}_{\mathrm{S}} / \mathrm{c}_{\mathrm{m}}$, ahol $\mathrm{c}_{\mathrm{s}}$ és $\mathrm{c}_{\mathrm{m}}$ a talajoldatban és a szennyezö fémsóoldatban mért koncentrációkat jelöli; Me: ld. 5. táblázat; Terhelési sorrend: $\mathrm{Cd}<\mathrm{Ni}<\mathrm{Cr}=\mathrm{Pb}<\mathrm{Zn}$; Visszanyerési \% sorrend: $\mathrm{Cr} \leq \mathrm{Pb}<<\mathrm{Ni} \cong \mathrm{Cd} \cong \mathrm{Zn} ;$ Mobilitási sorrend: $\mathrm{Cr}<\mathrm{Pb}<\mathrm{Ni} \cong \mathrm{Cd} \cong \mathrm{Zn}$ 


\section{Szennyvíziszap jelenlétének hatása}

$\mathrm{Az}$ iszap önmagában nagyobb mértékben kötötte meg a fémeket (a Ni kivételével), mint a viszonylag kis pufferkapacitású homoktalaj (vö. 7. táblázat a) és b) rendszer \% értékei). Szakirodalmi adatok is alátámasztják (ALLOWAY \& MORGAN, 1986; NoGALES et al., 1997), hogy míg például a Cd és Pb iszap jelenlétében kevésbé felvehetőek, a szennyvíziszaphoz adott Ni könnyen a talajoldatba kerül és a növények számára felvehetővé válik. A somogysárdi talajnál,

\section{7. táblázat}

Nehézfémek koncentrációja ( $\left.c_{s}, \mathrm{mg} / \mathrm{L}\right)$ a folyadékfázisban és megkötődése (\%)

a) a talaj /Somogysárd/, b) szennyvíziszap, c) talaj+szennyvíziszap rendszerben 100Me terhelési szint esetén

\begin{tabular}{|c|c|c|c|c|c|c|c|c|c|c|}
\hline \multirow{2}{*}{$\begin{array}{c}(1) \\
\text { Kezelés }\end{array}$} & \multicolumn{2}{|c|}{ Cd } & \multicolumn{2}{|c|}{$\mathrm{Cr}$} & \multicolumn{2}{|c|}{$\mathbf{N i}$} & \multicolumn{2}{|c|}{$\mathbf{P b}$} & \multicolumn{2}{|c|}{ Zn } \\
\hline & $\mathbf{c}_{\mathbf{S}}$ & $\%$ & $\mathbf{c}_{\mathrm{S}}$ & $\%$ & $\mathbf{c}_{\mathbf{S}}$ & $\%$ & $\mathbf{c}_{\mathbf{S}}$ & $\%$ & $\mathbf{c}_{\mathbf{S}}$ & $\%$ \\
\hline a) talaj+fém & 54 & 27 & 503 & 90 & 711 & 30 & 923 & 81 & 10660 & 30 \\
\hline b) iszap+fém & 2,7 & 96 & 41 & 99 & 854 & 16 & 29,5 & 99 & 8880 & 42 \\
\hline $\begin{array}{l}\text { c) talaj+ } \\
\text { (iszap+fém) }\end{array}$ & 0,86 & 99 & 2,3 & 100 & 365 & 64 & 7,2 & 100 & 2930 & 81 \\
\hline
\end{tabular}

Megjegyzés: nedvességpotenciál: $-20 \mathrm{kPa} ; \%=100 \cdot\left(\mathrm{c}_{\mathrm{m}}-\mathrm{c}_{\mathrm{S}}\right) / \mathrm{c}_{\mathrm{m}}$, ahol $\mathrm{c}_{\mathrm{S}}=$ elemkoncentrációk a talaj, az iszap és a talaj+iszap folyadékfázisában $(\mathrm{mg} / \mathrm{L}) ; \mathrm{c}_{\mathrm{m}}=$ elemkoncentrációk az alkalmazott modelloldatban $\left(\mathrm{mg} / \mathrm{L}^{*}\right)$; *: a $\mathrm{c}_{\mathrm{m}}$ érték kiszámításánál a b) és c) esetben az iszap saját nedvességtartalmát vettük figyelembe

szennyvíziszap jelenlétében a nehézfémek koncentrációja jóval, egyes esetekben nagyságrendekkel kisebb volt a talajoldatban, mint csak a fémsóoldat alkalmazásakor (vö. 7. táblázat a) és c) rendszer koncentráció értékei). A Cd-t és még inkább a $\mathrm{Cr}$-t és $\mathrm{Pb}$-t az iszap olyan nagy mértékben megkötötte, hogy adszorpciójuk alig változott a talaj+iszap-kezelés során (vö. 7. táblázat b) és c) rendszer \% értékei).

\section{Savterhelés hatása}

A savadagot növelve (a desztillált vizes kontrollkezelés, majd az 0,001;0,1 és $1,5 \mathrm{~mol} / \mathrm{L}$ koncentrációjú $\mathrm{HNO}_{3}$ oldat hatására), a pH csökkenésével a talajoldatban a nehézfémek koncentrációja többnyire nőtt, azonban 10-szeres nehézfémszennyezésnél, a Zn kivételével extrém nagy savterhelés (1,5 mol/ $\left.\mathrm{L} \mathrm{HNO}_{3}\right)$ volt szükséges a koncentrációk jelentős növelésére (2. ábra). Ennél a kezelésnél a talajoldatban a fémek koncentrációinak sorrendje megfelelt kiadott mennyiségük sorrendjének ( $\mathrm{Cd}<\mathrm{Ni}<\mathrm{Cr}=\mathrm{Pb}<\mathrm{Zn}$, 3. táblázat), bár a talajban erősen meg- 

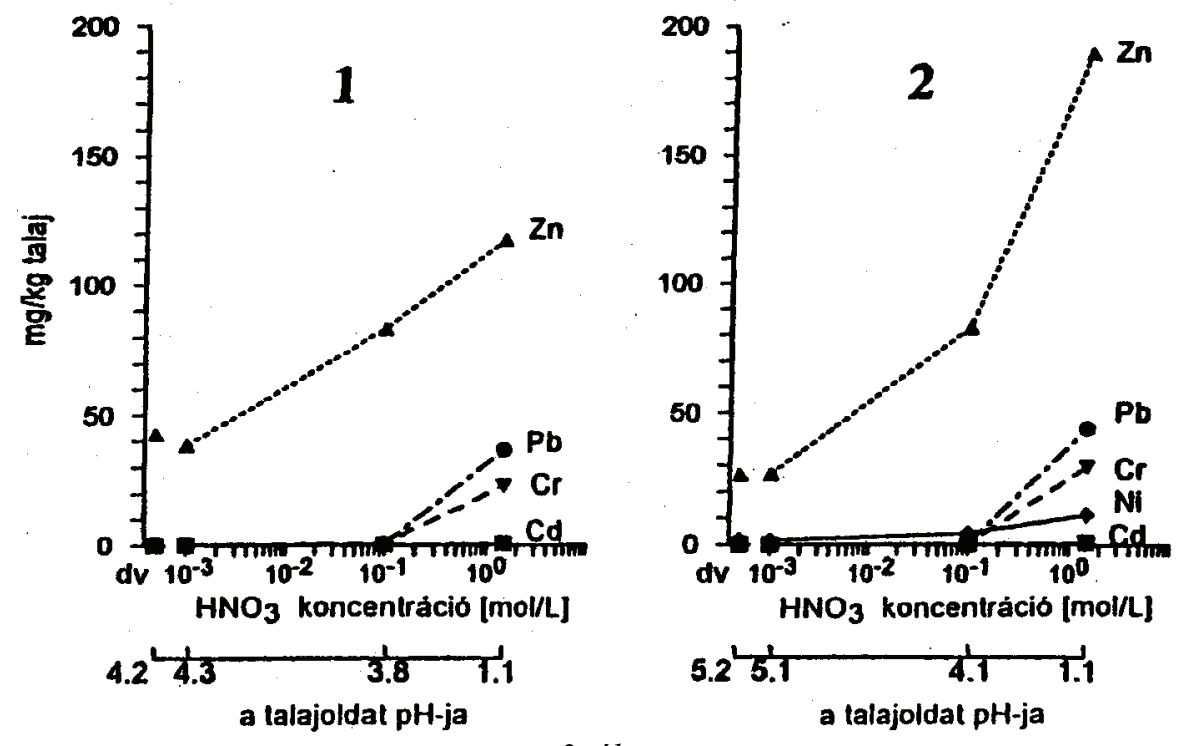

2. ábra

Elemkoncentrációk nehézfémmel terhelt (10Me), megszárított, majd savval kezelt talajok (1: Ragály, 2: Somogysárd) folyadékfázisában (nedvességpotenciál: $-20 \mathrm{kPa}$; dv: desztillált víz; $\mathrm{HNO}_{3}$ koncentrációk: 0,001; 0,1 és $1,5 \mathrm{~mol} / \mathrm{L}$ )

kötött $\mathrm{Pb}$ és különösképpen a $\mathrm{Cr}$ még $\mathrm{pH} \cong 1$-nél is viszonylag kisebb koncentrációban volt jelen a folyadékfázisban.

Ez jól látható a fémek visszanyerési hányadát (a talajoldat koncentrációt a hozzáadott mennyiség százalékában) kifejezve (3. ábra, 1., 2a): a talajhoz adott mennyiségből $\mathrm{pH} \cong 4$-nél a $\mathrm{Cd}$, Ni és $\mathrm{Zn} 20-35 \%$-a, míg a $\mathrm{Cr}$ és $\mathrm{Pb}$ kevesebb, mint $1 \%$-a került a talajoldatba. $\mathrm{pH} \cong 1$-nél a mozgékony elemek visszanyerési hányada a kötöttebb erdőtalajban $45 \%$, a homoktalajban 70-75\% volt, az igen kevéssé mozgékony Cr-nak pedig csak $25 \%$-a, illetve $35 \%$-a mobilizálódott még az extrém nagy savterhelés esetén is. 100-szoros nehézfémterhelésnél (3. Ábra, 2b) már a desztillált víz, illetve a viszonylag kisebb savadagok $(0,001$ és $0,1 \mathrm{~mol} / \mathrm{L} \mathrm{HNO}_{3}$-kezelés) hatására is az oldatfázisba került a talajhoz adott nehézfémek jelentős része, az erősen megkötődött $\mathrm{Cr}$ kivételével. A krómnak „csak” mintegy $35 \%$-a deszorbeálódott még az extrém fém- és savterhelés esetén is.

$\mathrm{Az}$ elemek kinyerhetőségének sorrendje $(\mathrm{Cr}<\mathrm{Pb}<\mathrm{Ni} \cong \mathrm{Cd} \cong \mathrm{Zn})$ nagyjából megfelelt a kationoknak az ásványok felületén történő specifikus adszorpciója, ill. az azt jellemző hidrolízis állandók (pK) sorrendjének $(\mathrm{Cr}(4,0)<\mathrm{Pb}(7,7)<$ Zn $(9,0)<\mathrm{Ni}(9,9)<\mathrm{Cd}(10,1)$; BRUEMMER et al., 1986; EVANS et al., 1995). A pK értékek és a fémek adszorpciója közti korreláció, mely standard rendszerek 

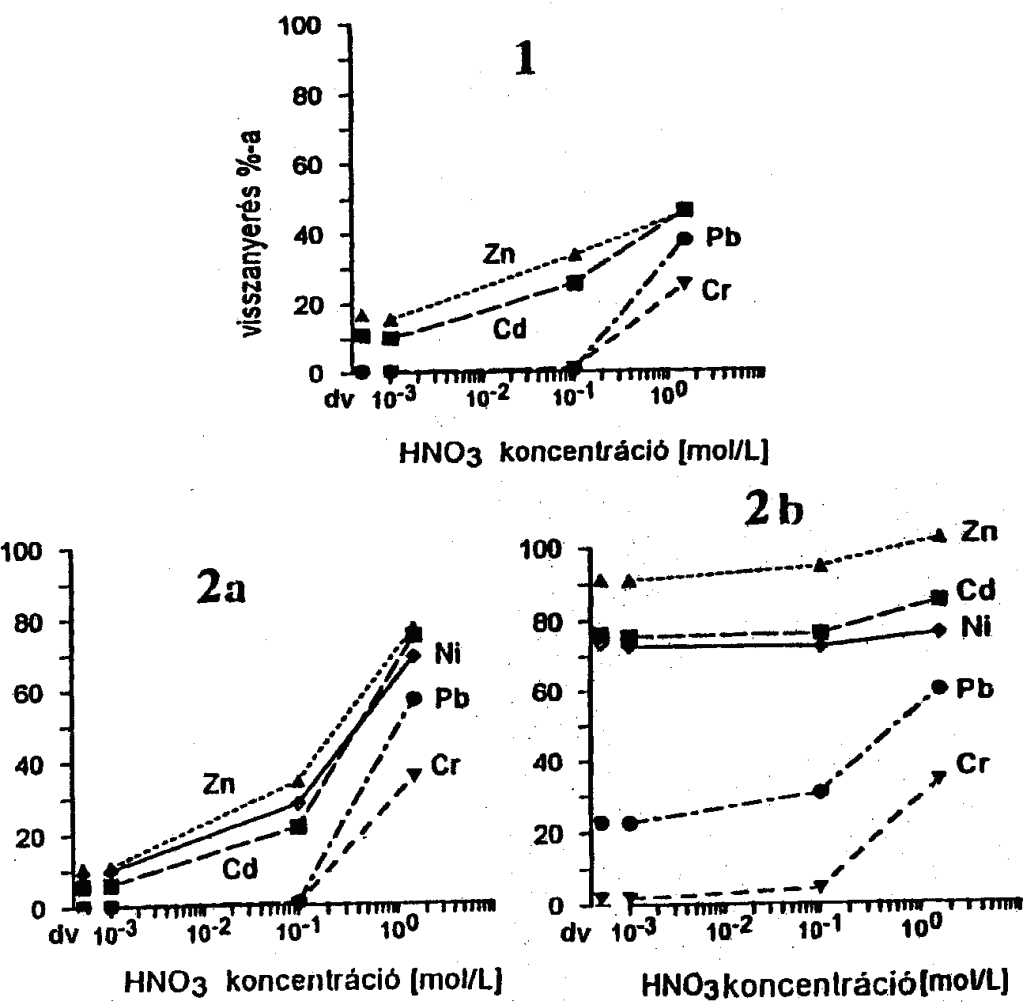

3. ábra

Nehézfémek visszanyerési \% értékei a savval terhelt talaj folyadékfázisában

(1: Ragály, 10Me; 2a: Somogysárd, 10Me; 2b: Somogysárd, 100Me)

$\%=100 \cdot c_{\mathrm{s}} / \mathrm{c}_{\mathrm{m}}$, ahol $\mathrm{c}_{\mathrm{s}}$ és $\mathrm{c}_{\mathrm{m}}$ a talajoldatban és a szennyező fémsóoldatban mért koncentráció; nedvességpotenciál: $-20 \mathrm{kPa}$

(pl. goethit) esetén áll fenn, összetett rendszerben számos tényező miatt módosulhat. Jelen kísérleti rendszerben a Cd, Ni és Zn egymáshoz hasonló adszorpciója, valamint $\mathrm{az} \mathrm{Pb}$ és még inkább a $\mathrm{Cr}$ igen erős megkötődése a talajban jól mutatja ezt a korrelációt. A Zn viszonylag kisebb mértékủ megkötődése (azaz nagyobb visszanyerési hányada, mely nem felel meg a hidrolízis állandók sorrendjének) részben azzal magyarázható, hogy a Zn koncentrációja a kísérleti rendszerben jóval meghaladta a többi elem koncentrációját.

\section{Következtetések}

A nehézfém- és savterhelések hatásával kapcsolatos, bolygatott szerkezetü talajokkal végzett kísérlet alapján összességében megállapítottuk, hogy a szabványban megengedett terhelésnél a talajoldatba jutó nehézfémek mennyisége 
elhanyagolható, túlnyomó részük a talajban megkötődik, immobilizálódik. Azt tapasztaltuk, hogy a nehézfémek, még a mobilisabb $\mathrm{Cd}$, Ni és $\mathrm{Zn}$ is, még a vizsgált kis pufferkapacitású homoktalaj esetén is csak extrém körülmények (provokatív túlterhelés és a talaj pH-jának nagymértékü csökkenése) esetén kerülnek jelentős mennyiségben a folyadékfázisba.

A kísérletekben alkalmazott igen nagymérvű nehézfém- és savterhelések gyakorlatilag nem fordulnak elö, a nem megfelelő kihelyezések, vagy illegális, illetve véletlen szennyezések azonban a szigorú környezetvédelmi elöírások ellenére sem zárhatók ki. Ezek a lokális felhalmozódások (,hot spots”) igen veszélyesek a környezetre, mert a talaj az óriási mennyiségü szennyezést már nem képes visszatartani, és a toxikus elemek nagy mennyiségben megjelenhetnek a folyadékfázisban. A nehézfémek talajbeli sorsáról (esetleges lemosódásukról a talajszelvényben, illetve elmozdulásukról a talaj telítetlen zónájában), valamint növényi felvehetőségükről további laboratóriumi és szabadföldi kísérletek nyújthatnak ismereteket.

\section{Összefoglalás}

A nehézfémek által okozott környezeti kockázat becslése céljából fontos annak ismerete, hogy azoknak mekkora hányada kerül a talaj folyadékfázisába. Hazai talajok felszíni rétegének mintáival kísérleteket végeztünk annak modellezésére, hogy különböző mértékü nehézfém- és savterhelések esetén, valamint szennyvíziszap jelenlétében illetve anélkül, mekkora a $\mathrm{Cd}, \mathrm{Cr}, \mathrm{Ni}, \mathrm{Pb}$ és $\mathrm{Zn}$ talajoldatba jutó (a környezetre különösen veszélyes) mennyisége.

A nehézfémterhelést nehézfémsó- (nitrát-) tartalmú többkomponensủ oldatokkal (a talajok szabadföldi vízkapacitásnak megfelelő nedvességtartalomra való benedvesítésével), a mezőgazdaságban felhasználható szennyvíziszapok megengedett fémtartalmának felső határát figyelembe véve végeztük. A megengedett (1-szeres, $1 \mathrm{Me}$ ) terhelésen kívül provokatív, 10-szeres és 100-szoros túlterhelést is alkalmaztunk (10Me és $100 \mathrm{Me})$, a nagymértékü helyi, pontszerü felhalmozódások hatásának modellezésére. A szennyvíziszap jelenlétének hatását fémsókkal dúsított kommunális szennyvíziszappal, 100Me terhelésnél vizsgáltuk. A savterhelés hatását $0 ; 0,001 ; 0,1$ és $1,5 \mathrm{~mol} / \mathrm{L}$ koncentrációjú $\mathrm{HNO}_{3}$ oldatokkal modelleztük, a szennyezett, majd megszárított talajok szabadföldi vízkapacitásnak megfelelő nedvességtartalomra történő újranedvesítésével. A talajban a -1500 és -20 kPa közötti erővel kötött folyadékfázist (a hasznosítható vizet) centrifugálással választottuk el, ily módon a szennyezett talaj nehézfémtartalmának legmobilisabb részét tudtuk becsülni.

A kísérletek alapján megállapítottuk, hogy a szabványban megengedett terhelésnél a talajoldatba jutó nehézfémek mennyisége elhanyagolhatóan kicsi, túlnyomó részük a talajban megkötődik, immobilizálódik. Még a mobilisabb 
$\mathrm{Cd}, \mathrm{Ni}$ és $\mathrm{Zn}$ is, a vizsgált kis pufferkapacitású homoktalaj esetén is csak extrém körülmények (provokatív túlterhelés és a talaj pH-jának nagymértékủ csökkenése) hatására kerülnek jelentős mennyiségben a folyadékfázisba. Szennyvíziszap jelenlétében a nehézfémek koncentrációja jóval, egyes esetekben nagyságrendekkel kisebb volt a talajoldatban, mint csak a fémsóoldat alkalmazásakor, és az iszap - a Ni kivételével - már önmagában is nagyobb mértékben kötötte meg a fémeket, mint a talaj.

A fenti kutatást az Országos Tudományos Kutatási Alap (OTKA) a T 023221 és a T 035101 sz. szerződés keretében támogatta.

\section{Irodalom}

AdRIANO, D. C., 1986. Trace Elements in the Terrestrial Environment. Springer-Verlag. New York.

AllowaY, B. J., 1997. The mobilisation of trace elements in soils. In: Contaminated Soils. 3rd Int. Conf. on the Biogeochemistry of Trace Elements. (Ed.: Prost, R.) 133-145. INRA. Paris.

Alloway, B. J. \& Morgan, H., 1986. The behaviour and availability of Cd, Ni, and $\mathrm{Pb}$ in polluted soils. In: Contaminated Soil. 1st. Int. TNO Conf. on Contaminated Soil. (Eds.: AssinK, J. W. \& VAN DEN BRINK, W. J.) 101-113. Martinus Nijhoff Publishers. Dordrecht.

Bruemmer, G. W., Gerth, J. \& Herms, U., 1986. Heavy metal species, mobility and availability in soils. Z. Pflanzenernaehr. Bodenk. 149. 382-398.

BufflaP, S. E. \& ALLEN, H. E., 1995. Comparison of pore water sampling techniques for trace metals. Wat. Res. 29. 2051-2054.

CAmpBell, D. J. \& BeCKeTt, P. H. T., 1988. The soil solution in a soil treated with digested sewage sludge. J. Soil Sci. 39. 283-298.

CsillaG, J. \& RÉDlY, M., 1989. Study of the liquid phase of the soil as a multicomponent electrolyte solution. Agrokémia és Talajtan. 38. 657-673.

CsillaG, J., Tóth, T. \& RÉDLY, M., 1995. Relationships between soil solution composition and soil water content of Hungarian salt-affected soils. Arid Soil Research and Rehabilitation. 9. 245-260.

CsillaG, J. et al., 1998. Release of $\mathrm{Cd}, \mathrm{Cr}, \mathrm{Ni}, \mathrm{Pb}$ and $\mathrm{Zn}$ to the soil solution as a consequence of soil contamination and acidification. Advances in GeoEcology. 31. 673-680.

CsiLlaG, J. et al., 1999. Extraction of soil solution for environmental analysis. Intern. J. Environ. Anal. Chem. 74. 305-324.

DEL CASTILHO, P., 1994. Validity of soil-solution samples from unsaturated soil, collected with various methods. Química Analítica. 13 (Suppl. 1). S21-S25.

Del CASTilho, P. et al., 1996. Effect of changes in soil factors on soil solution cadmium. Hrvat. Vode. 4. 125-134.

Evans, L. J., SpIers, G. A. \& ZhaO, G., 1995. Chemical aspects of heavy metal solubility with reference to sewage sludge amended soils. Intern. J. Environ. Anal. Chem. 59. 291-302. 
FILEP, GY., 1998. Behaviour and fate of pollutants in soil. In: Soil Pollution. (Ed.: FILEP, GY.) 21-49. Agricultural University of Debrecen, Debrecen.

FILEP, Gy., 1999. Soil Chemistry. Processes and Constituents. Akadémiai Kiadó. Budapest.

FÖRSTNER, U., 1988. Analysis and prognosis of metal mobility in soils and wastes. In: Contaminated Soil '88. Vol.1. (Eds.: Wolf, K., VAN DEN BrinK, W. J. \& COLON, F. J.) 1-10. Kluwer Acad. Publ. Dordrecht.

Fresenius, W., Quentin, K. E. \& Schneider, W. (Eds.), 1988. Water Analysis. A Practical Guide to Physico-Chemical, Chemical and Microbiological Water Examination and Quality Assurance. Springer-Verlag. Berlin.

GIESLER, R., LUNDSTRÖM, U. S. \& GRIP, H., 1996. Comparison of soil solution chemistry assessment using zero-tension lysimeters or centrifugation. European J. Soil Sci. 47. 395-405.

GoodDY, D. C. et al., 1995. Field-based partition coefficients for trace elements in soil solutions. European J. Soil Sci. 46. 265-285.

Goulding, K. W. T. \& Blake, L., 1998. Land use, liming and the mobilization of potentially toxic metals. Agriculture, Ecosystems \& Environment. 67. 135-144.

GYÖRI, Z. et al., 1996. Changes in the heavy metal contents of soil from the Park Grass Experiment at Rothamsted Experimental Station. Fresenius J. Anal. Chem. 354. 699-702.

KABATA-Pendias, A., 1995. Agricultural problems related to excessive trace metal contents of soils. In: Heavy Metals. Problems and Solutions. (Eds.: SALOMONS, W., FÖrstner, U. \& MADER, P.) 3-18. Springer. Berlin.

Kabata-Pendias, A. \& Pendias, H., 1990. Biogeochemistry of trace elements in the environment. In: New Horizons of Health Aspects of Elements. (Eds.: VOHORA, S. B. \& Dobrowolski, J. W.) 81-110. Hamdard University. New Delhi.

Kabata-Pendias, A. \& Pendias, H., 1992. Trace Elements in Soils and Plants. 2nd ed. CRC Press. Boca Raton. Florida.

KARUCZKA A. \& BLASKÓ L., 1993. Talajok savterheléssel szembeni érzékenysége és a potenciálisan toxikus elemek oldékonysága különböző talajokon. In: Országos Környezetvédelmi Konferencia, Siófok, 1993. szept. 7-9. 160-170.

Keller, C., 1995. Application of centrifuging to heavy metal studies in soil solutions. Commun. Soil Sci. Plant Anal. 26. 1621-1636.

LORENZ, S. E. et al., 1994. Applications of fertilizer cations affect cadmium and zinc concentrations in soil solutions and uptake by plants. European J. Soil Sci. 45. $159-165$.

MI-10-433/3-84. (L 09), 1984. Felszín alatti vizek minősége. Müszaki Irányelvek. Országos Vízügyi Hivatal. Budapest.

MI-08-1735-1990. (S 02), 1990. Szennyvizek és szennyvíziszapok termőföldön történő elhelyezése. MÉM Ágazati Müszaki Irányelv.

MSz 450/1-1989. (L 09), 1989. Ivóvíz. Minősítés fizikai és kémiai vizsgálat alapján. Országos Szabvány.

MSz 12749. (L 09/a), 1993. Felszíni vizek minősége, minőségi jellemzők és minősítés. Magyar szabvány.

MURÁNYI A. \& RÉDLY L-NÉ, 1986. Titrálási görbék felhasználása a talajt érő savterhelések hatásának összehasonlító jellemzésére. Agrokémia és Talajtan. 35. 49-62. 
NoGALES, R. et al., 1997. Metal extractability and availability in a soil after heavy application of either nickel or lead in different forms. Water, Air and Soil Pollution. 94. 33-44.

REDDY, K. J., WANG, L. \& GLOSS, S. P., 1995. Solubility and mobility of copper, zinc and lead in acidic environments. Plant and Soil. 171. 53-58.

Schulte, A., 1994. The adsorption of $\mathrm{Cd}, \mathrm{Zn}, \mathrm{Cu}$ and $\mathrm{Pb}$ in acid forest soils. In: Biogeochemistry of Trace Elements. (Ed.: ADRIANO, D. C.) Env. Geochemistry and Health 16. 525-535.

Smal, H., Misztal, M. \& BRIL, J., 2000. Soil solution chemistry in the profiles of forest and arable soils developed from loess. Polish J. Soil Sci. XXXIII. 47-56.

SoOn, Y. K. \& WARrEN, C. J., 1993. Soil solution. In: Soil Sampling and Methods of Analysis. (Ed.: CARTER, M. R.) 147-159. Lewis Publishers. Boca Raton.

SteFANOVITS, P., 1989. Effect of clay mineral content on soil acidification. In: Ecological Impact of Acidification. Proc. Joint Symp. „Environmental Threats to Forest and Other Natural Ecosystems" Nov. 1-4, 1988. Oulu, Finland (Ed.: SzABOLCS, I.) 49-59. Budapest.

Stigliani, W. M. et al., 1991. Chemical time bombs. Predicting the unpredictable. Environment. 33. 4-30.

SuAREZ, D. L., 1999. Thermodynamics of the soil solution. In: Soil Physical Chemistry. 2nd edition. (Ed.: SPARKS, D. L.) 97-134. CRC Press. Boca Raton.

TANJI, K. K. (Ed.), 1990. Agricultural Salinity Assessment and Management. American Society of Civil Engineers: ASCE Manuals and Reports on Engineering Practice No. 71. New York.

VÁRALLYAY GY. \& RÉDLY L-NÉ, 1977. Különböző erővel kötött nedvességfrakciók kémiai összetételének vizsgálata. Időszerü Öntözési Kutatások. 1976. 39-42. VITUKI. Budapest.

VÁRAllyay, G., RÉDly, M. \& MurÁNYI, A., 1989. Map of the susceptibility of soils to acidification in Hungary. In: Ecological Impact of Acidification. Proc. Joint Symp. „Environmental Threats to Forest and Other Natural Ecosystems” Nov. 14, 1988. Oulu, Finland (Ed.: SzABOLCS, I.) 79-94. Budapest.

WelP, G. \& BRÜMMER, G. W., 1999. Adsorption and solubility of ten metals in soil samples of different composition. J. Plant. Nutr. Soil Sci. 162. 155-161.

Wolt, J. D., 1994. Soil Solution Chemistry. Applications to Environmental Science and Agriculture. John Wiley \& Sons. New York.

ZABOWski, D. \& UGOLINI, F. C., 1990. Lysimeter and centrifuge soil solutions: Seasonal differences between methods. Soil Sci. Soc. Am. J. 54. 1130-1135.

Yong, R. N., Mohamed, A. M. O. \& Warkentin, B. P., 1992. Principles of Contaminant Transport in Soils (Developments in Geotechnical Engineering. 73) Elsevier. Amsterdam.

Érkezett: 2001. június 7. 


\title{
Changes in the $\mathrm{Cd}, \mathrm{Cr}, \mathrm{Ni}, \mathrm{Pb}$ and $\mathrm{Zn}$ Concentrations in the Soil Solution as the Result of Metal and Acid Loads under Laboratory Conditions
}

\author{
J. CSILLAG, A. LUKÁCS, K. BUJTÁS and G. PÁRTAY \\ Research Institute for Soil Science and Agricultural Chemistry of the \\ Hungarian Academy of Sciences, Budapest
}

\section{Summary}

For the estimation of the environmental risk caused by heavy metals it is important to know what proportion of these metals enters the liquid phase of the soil. Experiments were carried out on samples taken from the surface layers of Hungarian soils in order to model the quantities of $\mathrm{Cd}, \mathrm{Cr}, \mathrm{Ni}, \mathrm{Pb}$ and $\mathrm{Zn}$ entering the soil solution (and thus representing a special danger to the environment) in the case of different heavy metal and acid loads as well as in the presence or absence of sewage sludge.

The heavy metal treatments involved multicomponent solutions of heavy metal salts (nitrate) with which the soils were moistened to field water capacity, taking into consideration the upper limits of metal contents permitted in the sewage sludge used in agriculture. In addition to the permitted level of pollution $(1 \mathrm{Me})$, tests were also made with 10 -fold $(10 \mathrm{Me})$ and 100 -fold $(100 \mathrm{Me})$ loading levels in order to model the localized accumulation of contaminants. The effect of the presence of sewage sludge was studied by adding metal salts to communal sewage sludge at the $100 \mathrm{Me}$ level. The effect of acid loads was modelled using $0,0.001,0.1$ and $1.5 \mathrm{~mol} / \mathrm{L} \mathrm{HNO}_{3}$ solutions, with which the contaminated then dried soils were remoistened to field capacity. The liquid phase (available water) retained in the soil with -1500 to $-20 \mathrm{kPa}$ strengths was separated by centrifugation, thus allowing the most mobile portion of the heavy metal content of contaminated soils to be estimated.

On the basis of the experiments it was found that the quantity of heavy metals entering the soil solution at the pollution level permitted in the standard was negligible, since the vast majority of the metals was adsorbed, immobilized by the soil. Even the mobile elements, $\mathrm{Cd}, \mathrm{Ni}$ and $\mathrm{Zn}$, entered the liquid phase in significant quantities only under extreme conditions (excessive contamination or a great decrease in soil $\mathrm{pH}$ ) even in the sandy soil, which has very low buffering capacity. In the presence of sewage sludge the concentration of heavy metals was much lower in the soil solution (in some cases by several orders of magnitude) than when heavy metal salt solutions were applied alone. Except in the case of Ni, the sewage sludge itself adsorbed the metals to a greater extent than the soil.

Table 1. Methods for the extraction of the soil liquid phase. (1) Methods. (2) Advantages. (3) Limitations. A. In situ extraction techniques. A) Free-drainage soil solution sampling; b) Vacuum suction sampling method; c) extraction of the liquid phase at natural state, from undisturbed soil; d) solution can be obtained only from a fairly wet light-textured soil; e) maximum suction cannot be greater than the atmospheric pressure $(-100 \mathrm{kPa})$, while plants can exert much higher suctions (conventional wilting point: $-1500 \mathrm{kPa}$ ). B. Laboratory methods (from undisturbed soil or from air-dried, ground, rewetted soil samples). f) Displacement in column with organic solvents; 
g) centrifugation with immiscible liquid; h) extraction of strongly retained liquid phase of relatively dry soils is also possible; i) the energy status of the solution remaining in the soil after extraction is not defined; $j$ ) the immiscible liquids may be volatile and toxic; k) hydraulic pressing; 1 ) extraction of the soil solution is possible even at very low soil water content; $m$ ) the extreme high pressures disturb the equilibria between the soil phases; n) pressure membrane filtration; o) high speed centrifugation; $p$ ) characterization of the energy status of the solution to be extracted from the soil is possible; q) RISSAC method: for the extraction the conventional upper limit of the suction exerted by plant roots is modelled $\rightarrow$ plant available soil solution can be extracted; r) the cellophane membrane in the pressure membrane apparatus adsorbs part of the dissolved heavy metals.

Table 2. Main physical and chemical properties of the soils. (1) Soil. (2) Depth, cm. (3) Humus, \%. (4) T value (cation exchange capacity), meq/100 g. Soils: 1: acidic brown forest soil with clay illuviations, Ragály. 2: weakly acidic humous sandy soil, Somogysárd. 3: chernozem soil, Pusztaszabolcs. $<0.02 \mathrm{~mm}=$ silt+clay fraction; $<0.002$ $\mathrm{mm}=$ clay fraction .

Table 3. Upper limit of metal contents permitted in the sewage sludge used in agriculture (MI-08-1735-1990 Technical Guidelines published by the Ministry of Agriculture and Food Industry). (1) Element. (2) In the sludge, $\mathrm{mg} / \mathrm{kg}$ dry matter. (3) Resulting soil contamination level $(1 \mathrm{Me}), \mathrm{mg} / \mathrm{kg}$ soil*. Note: $* 500 \mathrm{t} / \mathrm{ha}$ sewage sludge with a $5 \%$ dry matter content, incorporated into the upper $20 \mathrm{~cm}$ soil layer (calculated value).

Table 4. Errors of the method applied to extract the soil solution: element concentrations $(\mathrm{mg} / \mathrm{L})$ of the liquid phase at soil moisture contents equivalent to field and maximum water capacities (acidic brown forest soil with clay illuviations, Ragály, 100Me). (1) Statistical parameter. (2) Elements. Note: $n=$ number of replications $=5$; $x$ $=$ mean value; $\mathrm{s}=$ standard deviation; $\mathrm{CV}$ : coefficient of variance, $\%$; $\mathrm{h}$ : confidence limits at the $\mathrm{t}_{5 \%}$ level of significance.

Table 5. Element concentrations $(\mathrm{mg} / \mathrm{L})$ of the liquid phase of the soil at various heavy metal loads. (1) Loads. For A-C: Soils, See Table 2. Note: $<$ kh: below the detection limit; - not measured; 0Me: untreated soil; $1 \mathrm{Me}, 10 \mathrm{Me}$ and $100 \mathrm{Me}: 1-, 10$ and 100-fold values of the maximum heavy metal pollution levels permitted in sewage sludge; loads: with multicomponent solutions of heavy metal nitrates; moisture potential: $-20 \mathrm{kPa}$.

Table 6. Limit values of element concentrations in waters $(\mathrm{mg} / \mathrm{L})$ : ivóvíz $=$ drinking water; folyóvíz = river water; felszíni vizek = surface water; felszín alatti vizek = subsurface water; talajvíz = groundwater; öntözővíz = irrigation water.

Table 7. Heavy metal concentration $\left(\mathrm{c}_{\mathrm{s}}, \mathrm{mg} / \mathrm{L}\right)$ in the liquid phase and its adsorption (\%) in the a) soil (Somogysárd), b) sewage sludge and c) soil+sewage sludge system. (1) Treatment a) soil + heavy metal; b) sludge + heavy metal; c) soil + (sludge + heavy metal). Note: moisture potential: $-20 \mathrm{kPa}$. $\mathrm{c}_{\mathrm{s}}$ : element concentrations in the liquid phase of soil, sludge and soils + sludge $(\mathrm{mg} / \mathrm{L}) ; \mathrm{c}_{\mathrm{m}}$ : element concentrations in the model solution applied $\left(\mathrm{mg} / \mathrm{L}^{*}\right)$; $*$ In calculating the $\mathrm{c}_{\mathrm{m}}$ value the moisture content of the sewage sludge itself was used in cases $b$ ) and c). 
Fig. 1. Heavy metal concentrations in the liquid phase of the soil, as percentage pollution. For $\mathrm{c}_{\mathrm{s}}$ and $\mathrm{c}_{\mathrm{m}}$ : See Table 7; Me: see Table 5. Contamination order; Recovery $\%$ order; Mobility order.

Fig. 2. Element concentrations in the liquid phase of soils from Ragály (1) and Somogysárd (2) contaminated with heavy metal (10Me), dried and then treated with acid. (Moisture potential: $-20 \mathrm{kPa}$, dv: distilled water, $\mathrm{HNO}_{3}$ concentrations: 0.001, 0.1 and $1.5 \mathrm{~mol} / \mathrm{L}$.

Fig. 3. Heavy metal recovery \% values in the liquid phase of soils contaminated, then treated with acid. 1. Ragály, 10Me, 2a. Somogysárd, 10Me, 2b. Somogysárd, $100 \mathrm{Me}$. For $\mathrm{c}_{\mathrm{s}}$ and $\mathrm{c}_{\mathrm{m}}$ : See Table 7 